\title{
Materials Research Activities in Europe
}

\section{Course on Crystal Growth Held at International School of Erice, Italy}

The Ettore Majorana International Center in Erice, Sicily is well known for its activity in promoting scientific culture, international conferences, and schools. Every year the school program includes some specific courses devoted to materials science. The subject of the 13th course of the International School of Crystallography, held in September 1987, was "Crystal Growth in Science and Technology"

The aim of the school was to stress the interdisciplinary nature of the subject, reviewing on an advanced tutorial level selected fundamental principles of crystal growth and analyzing important crosslinks between a variety of basic and applied aspects.

Twenty-six selected lecturers, members of the main research institutions of the United States and Europe, covered the main aspects of crystal growth science and its applications in industrial crystallization. The two-week course was attended by more than 100 young scientists working on different crystal growth problems in both basic research and industry. There were particularly lively discussions about new ceramic superconductors, advanced technologies for epitaxial layer preparation, and innovative methods for low-cost, high-perfection large semiconducting compound crystals. Crystal shaping processes, dendritic growth and analysis of twinning formation were the other main topics of the course.

The Erice medieval atmosphere, the splendid Sicilian beaches, and the lovely social life organized by Prof. L. Riva di Sanseverino and his secretarial committee greatly contributed to the success of the course. The course was sponsored by NATO and by the Italian National Research Council (Consiglio Nazionale delle Ricerche). Prof. Hans Arend from Zurich Politechnical was the director.

L. Zanotti MASPEC-CNR Parma, Italy

\section{Eighth European Photovoltaic Solar Energy Conference to be Held in Florence, Italy}

The Eighth European Photovoltaic Solar Energy Conference will be held May 913, 1988 in Florence, Italy. Sponsored by the Commission of the European Communities, the conference will cover all aspects of the photovoltaic activities from laboratory devices to whole photovoltaic systems, materials research to economic and market analysis, and university research to industrial production. Progress in storage techniques has been added to the list of subjects for invited and contributed papers, and an exhibition will give industries an opportunity to present their latest achievements.

Italy, the host country of the conference, has an established tradition in the applications of solar energy. Having conducted pioneering activities in photovoltaics, Italy now has an ambitious program of research and development covering crystalline solar cells as well as thin-film techniques.

The conference program will cover the following subjects:

1. Materials research-fundamental studies on materials, theories, diagnostics, low-cost feedstocks, sliced sheets, and ribbons.

2. Crystalline devices-silicon and other semiconductors.

3. Thin-film devices-amorphous silicon, alternative cells and thin-film deposition on crystalline substrates.

4. Applications and system development-systems and their components, including array structures, control and storage; utility interface issues, including power quality; appropriate systems for remote uses, maximizing energy output, including energy efficient equipment and appliances; market analyses; and system modeling.

5. Tests and trials-performance rating of cells, modules, arrays, and simulators; test procedures, norms and standards; calibration of sensors and PV devices; systems monitoring techniques; and experiences with data acquisition systems.

6. Advanced storage for photovoltaicsnew batteries, fly-wheels, hydrogen technology, etc.

For information contact:

WIP, Sylvensteinstrasse 2

D-8000 Munich 70

W. Germany

\section{Zanotti MASPEC-CNR Parma, Italy}

National Research Council of Italy Sponsors Research on Materials and Devices for Solid State Electronics

Since 1986 the National Research Council, Consiglio Nazionale delle Ricerche (CNR), of Italy has supported a national research program for developing $\mathrm{mi}$ croelectronic materials and devices. In five years this project will support basic and applied research, with an overall budget of 126.2 billion lire (about $\$ 100$ million U.S.). The goal of this project is to coordinate and implement research carried out by industrial companies, universities, and CNR institutes on solid state electronics. In 1987, 64 industrial groups, 80 university groups, and 51 CNR groups were engaged in research to develop microelectronic materials and devices. These participants include nearly all the scientific and technological community 
active in this field in Italy

The finalized project, "Materials and Devices for Solid State Electronics," was approved by the Committee for Economic Planning in March 1985 on the basis of the feasibility study by a commission of experts appointed by CNR. The general criteria of the feasibility study were:

1. Maximum possible precision in identifying objectives, times and necessary resources;

2. Strict connection and integration with other national projects (electrooptical technologies, telecommunications, new advanced materials);

3. Coordination with European Economic Community programs (ESPRIT, RACE) operating in the same or nearby areas;

4. Balanced and coordinated participation of research institutions and industrial firms in order to reach each objective and also to lay the basis for efficient innovation transfer.

The project's director is Prof. A. Paoletti, chairman of the engineering faculty of the 2nd University of Rome. The assistant director is Prof. B. Antonini of Istituto Elettronica Stato Solido CNR.

Sub-projects are under the responsibility of five leading scientists from universities and industries: Professors G. Asti, A. D'Amico, E. Rimini, and V. Svelto, and Dr. Ing. G. Zocchi. Five main sub-projects have been identified, each with the following themes:

1. VLSI microstructures (technological processes, physics and models, architecture and $(A \mathrm{D})$;

2. Materials and devices for microwaves and optoelectronics (high-mobility structures and HEMT devices, 20-30 GHz monolithic circuits, magnetic materials and devices, materials and devices for optical communications, optical signal elaboration, guided optics, and IR sensors);

3. Semiconductor power devices (highpower devices, power-transistor modules, medium- and low-current GTO devices, and other applications);

4. Sensors (intelligent, chemical, thickfilm, thin-film, and movement sensors);

5. Diagnostics and reliability (diagnos-. tics, functional characterization, physics of breakdown, strain techniques, and mathematical models).

All the major companies active in Italy in microelectronics and most of the companies active in telecommunications are participating in the research project with their best scientists and technologists. Industrial research groups participate in nearly all themes in every sub-project, with peaks in VLSI, power devices, and reliability.

In contrast, the participation of univer- sity groups in research projects involving advanced technologies is rather low, testifying to an increasing and troubling difficulty to perform advanced technological research in the universities. Participation of the CNR Institutes is appreciable and confirms the effectiveness of investments carried out by the Institution to establish good research centers in microelectronics.

The distribution of funds is as follows: $50 \%$ to industries, and $50 \%$ in equal parts to CNR and universities.

Participation of research groups in southern Italy is significant, although concentrated in a few cities and with a slender fraction (9\%) of total funds when compared with attainment of a reasonable territorial equilibrium.

\section{MASPEC-CNR Parma, Italy}

L. Zanotti

\section{Materials Get High Priority in Portugal's Research Program}

A committee nominated by JNICT Uunta Nacional de Investigação Científica e Tecnológica) has been made responsible for establishing the guidelines for a Materials Development Program for Portugal. After several meetings and taking into account the dimensions of the research teams and the equipment available, the committee agreed that the principal criteria for a research and development program are that more than one team participate in projects and that projects which clearly involve industrial participation should be favored when they are related to applied research and development. Regarding training and materials education, it was deemed desirable to create a postgraduate-type course with reduced academic content and geared to partical research. Action involving the participation of postgraduates in productive activity was also recommended.

After identifying deficiencies in Portugal in terms of research in new materials and modern technologies, the committee stimulated actions in the following areas:

1. Composite materials reinforced with fibers and/or particles for structural applications;

2. Finishing/processing to increase resistance to chemical abrasion and corrosion of surfaces;

3. Structural adhesives for binding different materials;

4. Materials with high mechanical resistance at high temperatures;

5. Materials for electronics, telecommunications, and techniques;

6. Production of glass and ceramics by unconventional techniques;

7. Synthesis of new polymers and their properties and applications; and

8. Improvement of materials incorporating tungsten.

Taking into account the deficiencies in basic materials research activity and the need for interdisciplinary teams including materials specialists, physicists and chemists, the committee is encouraging projects for more basic research in two areas:

1. Surfaces/interfaces and their correlation with the behavior of materials, particularly metal/ceramic interfaces, polymer/nonpolymer interfaces, fiber/ matrix interfaces, electric (electronic) properties of interfaces and surfaces, chemical properties of interfaces and surfaces, theoretical studies on surfaces and interfaces (structure and properties), and theoretical/practical studies of physical and chemical interconnection of interfaces obtained by advanced processing (laser, ion implantation, CVD, earth-gel etc.); and

2. Electrical, magnetic optical, and thermal properties of solids, including amorphous solids.

The role of international collaboration is crucial for Portugal at the present time. Joint projects, particularly projects attractive for industry, can be funded very easily. Because Portugal has serious deficiencies in modern equipment, projects involving the introduction of new equipment for ion implantation, ion beam characterization of materials, and materials synthesis are highly encouraged. Launching some of these projects will also involve the organization of workshops and schools where the collaboration of leading scientists from different fields is welcome.

J.C. Soares

University of Lisbon Lisbon, Portgual

\section{Upcoming}

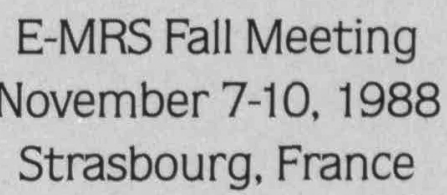

Superconductors

and

Magnets 